\title{
Reliability Estimation for Double Containment Piping
}

\section{0th ANS Topical Meeting on the Technology of Fusion Energy}

\author{
L. Cadwallader
}

T. Pinna

\section{August 2012}

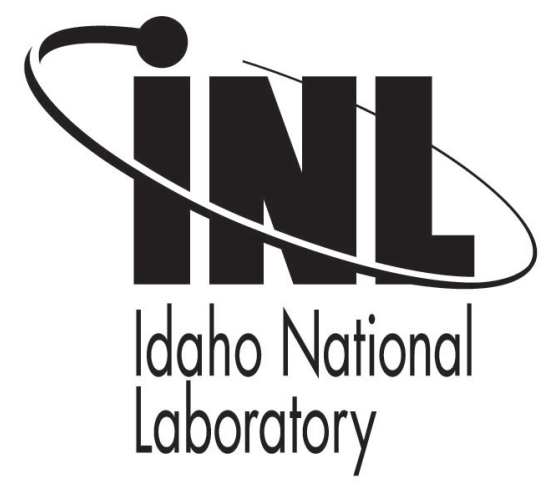

This is a preprint of a paper intended for publication in a journal or proceedings. Since changes may be made before publication, this preprint should not be cited or reproduced without permission of the author. This document was prepared as an account of work sponsored by an agency of the United States Government. Neither the United States Government nor any agency thereof, or any of their employees, makes any warranty, expressed or implied, or assumes any legal liability or responsibility for any third party's use, or the results of such use, of any information, apparatus, product or process disclosed in this report, or represents that its use by such third party would not infringe privately owned rights. The views expressed in this paper are not necessarily those of the United States Government or the sponsoring agency. 


\title{
RELIABILITY ESTIMATION FOR DOUBLE CONTAINMENT PIPING
}

\author{
L. Cadwallader ${ }^{\mathrm{a}}$ and T. Pinna ${ }^{\mathrm{b}}$ \\ a) Idaho National Laboratory, PO Box 1625, Idaho Falls, ID 83415 USA \\ b) ENEA, via Enrico Fermi 45, I-00044, Frascati (Rome), Italy
}

Double walled or double containment piping is considered for use in the ITER international project and other next-generation fusion device designs to provide an extra barrier for tritium gas and other radioactive materials. The extra barrier improves confinement of these materials and enhances safety of the facility. This paper describes some of the design challenges in designing double containment piping systems. There is also a brief review of a few operating experiences of double walled piping used with hazardous chemicals in different industries. The authors recommend approaches for the reliability analyst to use to quantify leakage from a double containment piping system in conceptual and more advanced designs. The paper also cites quantitative data that can be used to support such reliability analyses.

\section{INTRODUCTION}

Placing a process pipe, also called a carrier pipe, within a larger, or outer, pipe to serve as an additional containment barrier, has been successfully used in several industries. The elements of a double containment piping system are shown in Figure 1.



Fig. 1. Features of double containment piping.

The double pipe design approach has been referred to as pipe-in-pipe (PiP), double-walled piping, double containment piping, jacketed piping, enclosed piping, and other names.

In the US, this two pipe approach is usually referred to as secondary containment and is given as a design option to confine hazardous liquid chemicals for both underground and above ground tanks and piping. ${ }^{1,2}$ There can be three configurations to operate the outer piping: pressurized, vacuum, and purge. ${ }^{3}$ In the former, the outer pipe is sealed at both ends and the annular space is pressurized to greater than the pressure of the process fluid in the carrier pipe. If the carrier pipe experiences a leak, there will be a net flow of the pressurization gas (often nitrogen, sometimes argon or helium) into the carrier pipe. A pressure transducer in the annular space is set up to signal this condition. The loss of annular gas pressure may be due to a leak of the outer pipe; this possibility must be taken into account.

In the vacuum mode, the outer pipe is again sealed but this time contains some fluid (air or another gas) at subatmospheric pressure. This configuration can be advantageous when the carrier pipe must be thermally insulated. A pressure transducer is set up to signal if pressure increases because of carrier pipe leakage. This operating mode also shares the issue that if the outer pipe leaks, the incoming air will cause a pressure alarm rather than the process fluid causing an alarm.

The third configuration is purge operation. Purging is usually performed with a pressurized carrier pipe. The annular space between the pipes is continually swept with a low, but above atmospheric pressure gas, and the purge gas is monitored for fluid leakage from the carrier pipe. In the gas purging method, the monitor could be a specific chemical monitor to sense carrier pipe fluid leakage.

This paper investigates the means available to the analyst to estimate the reliability of double containment piping against leakage and makes recommendations on the best approaches to use to quantify reliability of such piping designs.

\section{DOUBLE CONTAINMENT PIPING DESIGN}

There are several design guides available to the system designer who chooses to employ double containment piping. ${ }^{4-7}$ Given that this confinement design approach is typically a modest cost relative to other 
approaches (e.g., concrete lined trench enclosure, designated enclosure rooms), there are a fairly high number of such systems in operation. Typical industrial systems follow governmental regulations and use centering rings or spacers in the annulus, leak detection cables in the annulus, and assume that the secondary pipe can adequately confine a process fluid leak for up to 30 days without leakage to the environment. Fusion facilities also use double containment. ${ }^{8}$ Double containment improves safety against leaks but also presents tradeoffs. If carrier pipe maintenance or inspection is required, there will generally be greater maintenance time with double containment piping - this reduces system availability. If the piping is in a radiation field, then there is also higher occupational radiation exposure from the longer maintenance time.

The US federal rule on double containment piping specifies that the inner space or annulus must be monitored for leakage. ${ }^{2}$ Detectors in the annulus must be able to detect liquid leaks of $\geq 0.19 \mathrm{~L} / \mathrm{min}$ ( $3 \mathrm{gal} / \mathrm{hr}$ ) or a pressure change of $68,948 \mathrm{~Pa}(10 \mathrm{psi})$ within one hour of leak inception in the annulus between pipes; the detectors must be tested annually. Many applications use either a conductive or resistance-based leak detection cable, or else use a periodic sampling procedure from a low point drain in the piping to achieve this requirement. Some users dislike the manpower-intensive periodic sampling and prefer the cables. Cable systems are stated to have an accuracy of $\pm 1 \%$ of the total cable length. ${ }^{9}$ Some users have reported that condensation from humid air has formed in the annulus and created false alarms from the detection cables.

The American Society of Mechanical Engineers' piping inspection code for fission power plants states that pipe welds are exempt from examination if they are encapsulated by guard pipe. ${ }^{10}$ In some safety significant applications, however, the regulator may insist that piping welds be inspected periodically despite the code exemption. In one nuclear fission power plant with a guard pipe around the $1-\mathrm{m}$ diameter steam generator outlet pipe, access was needed to perform radiographic inspection of the welds. Personnel placed blank flanges in the guard pipe to allow personnel access to the carrier pipe. ${ }^{11}$ If carrier pipe inspection is necessary, this would appear to be a feasible means to accomplish weld radiography or ultrasonic inspection as well as a very limited visual inspection of the carrier pipe exterior. A second option is a commercial off-the-shelf technology called 'ultrasonic guided wave technology' for inspecting the carrier pipe. Liu discusses the advantages of this method where a transducer can be left in place on the carrier pipe to facilitate periodic inspections. ${ }^{12}$ Another possibility is robotic inspection of the carrier pipe by inserting the inspection robot so that it traverses carrier pipe interior. This would mean draining and opening the pipe for robot entry and exit, which may not be desirable for a quick return to operation. Generally, the annulus between pipes has too many obstructions (pipe centering supports or spacers, instrumentation taps, perhaps a leak detection cable, etc.) to allow robotic inspection of the exterior of the carrier pipe from the annulus.

Ziu described another challenge for secondary containment piping design. ${ }^{13}$ Ziu states that thermal expansion, if not compensated for properly in piping design, can cause a double-containment piping system to have a shorter service life than a properly designed single wall pipe, at least for plastic piping. Given the coefficients of thermal expansion of metals, there is certainly concern about this issue for metal pipes as well. Differential expansion of inner and outer piping can cause reaction loads at interconnecting components. Figure 2 gives an illustration of thermal expansion induced component contact.



Fig. 2. Carrier pipe thermal expansion resulting in contact with the secondary pipe (Ref. 5).

The loads at these contacts can produce tensile stresses that approach the yield strength of the pipe materials and induce stress cracking at the interconnection points. These loads can lead to inner and outer pipe failure.

Ziu discusses that thermal expansion of the two pipes, the carrier and the containment pipes, will differ for two primary reasons. ${ }^{4}$ The first reason is if the carrier pipe holds a hot fluid, its temperature will always be higher than the outer pipe. With temperature mismatch, the linear thermal expansion will be greater for the carrier pipe, so the carrier pipe will expand more than the containment pipe. Great care is needed in the design of these systems despite the fact that any facility will place constraints on space given to route the larger diameter outer pipe. When in underground applications, the outer pipe could be in contact with the earth, and the pipe could be held at a reasonably constant low temperature of 
perhaps $10^{\circ} \mathrm{C}$ depending on the depth and the thermal conductivity of the soil at the location.

The second reason for differing thermal expansion between pipes is that the two pipes may be constructed of different materials. The idea behind materials selection is that the outer pipe may be neither challenged to contain leaks very often nor required to contain the leaking fluid for very long times (e.g., the governmental requirement of 30 days), so the outer pipe could be constructed more inexpensively if it were made of a less strong material, such as plastic. Indeed, many hazardous chemical systems use fiberglass or plastic pipe as the outer pipe. The outer pipe does have to meet basic chemical compatibility and fluid pressure requirements. If the two materials used in carrier and outer piping vary greatly, then the mismatch of their thermal expansion may be large, which poses design concerns.

Another concern with double containment piping is vibration, usually flow-induced vibration in the carrier pipe. The vibration is transferred by centering rings or restraints to the outer pipe or when the carrier pipe is sliplined into the outer pipe. The carrier pipe typically cannot be seen or easily inspected, so it can experience premature failure from vibration. For plastic pipes, Ziu states that vibration has been a failure cause leading to premature failure within the first year of operations. ${ }^{13}$ Futukawa studied vibration in a gas-cooled fission reactor double walled pipe. ${ }^{14}$ He concluded that vibration characteristics varied considerably with the locations of the spacers used to keep the pipe walls apart. The damping ratio of the coaxial double pipe increased with the number of supporting points and was larger than that of a single pipe.

An additional concern with double piping is corrosion because the carrier pipe is difficult to inspect for issues such as erosion-corrosion wall thinning or even surface corrosion. There are design provisions, such as cathodic protection, available to address corrosion concerns. Depending on the pipe material, keeping the annulus gas free of moisture can also be an important part of corrosion protection.

\section{RELIABILITY APPROACHES FOR DOUBLE CONTAINMENT PIPING}

Ostensibly, adding a second, independent pipe wall should mean that the chance of leakage (either outward or inward) should be treated as two independent confinement barriers. Therefore, two-pipe leakage failure rates on the order of $\approx 1 \mathrm{E}-08 / \mathrm{hr}-\mathrm{m}$ or lower are combined by an AND gate to give a result that is a vanishingly small rate of leakage to the environment given the constraints of pipe length and mission time. The fusion Blanket
Comparison and Selection Study approached double wall coolant tubing (a tube sleeved on another tube) in this manner, giving double wall reliability, $\mathrm{R}$, as $\mathrm{R}=1-$ (number of failed tubes/total number of coolant tubes) (Ref. 15). That is, the reliability equation assumed that the tube wall failures were independent and no common mode failures were assumed to occur. That is perhaps the most important assumption in regard to assessing the reliability of double containment piping. This assumption has been found in a wide variety of studies (for example, Refs 16, 17).

Some analysts have modeled the outer pipe as an unchallenged standby component until a leak of the carrier pipe has occurred. This is because the outer pipe must operate for only a short duration of challenge until the system is shut down, repairs are made to the carrier pipe, and the outer pipe is flushed and cleaned. The short duration could be on the order of 1 hour for a sensor to give an alarm and then the plant proceeds to an orderly shutdown that could perhaps require up to another 24 hours (or 30 days can be used). If the environmental factors of the standby pipe component (vibration effects, corrosion effects, etc.) are properly accounted for in a standby component model, then this is a sound approach to estimating the reliability of a double-walled piping system.

Literature searches were performed to identify operating experiences that would indicate failure rates of double containment piping. Despite the fact that double containment systems have been widely used in the chemical industry since the 1990 s, very little information was found in the literature. There is some qualitative information that industrial systems overall have performed very well. ${ }^{18-20}$ Two additional cases are described below. No data sets were found that could serve as a basis for a failure rate calculation. Therefore, either modeling or analyst judgment is needed to determine the reliability. Analyst judgment approaches vary in the risk literature from assuming independent piping to a conservative common-cause type approach of a 0.5 multiplier on the failure rate of single walled piping to account for the secondary containment pipe. ${ }^{21}$

Kumagai gives an important case history. ${ }^{22}$ He stated that for double containment piping used in the semiconductor industry, the reactant gas is contained in the carrier pipe while the outer pipe provides mechanical protection as well as acts as a containment for reactant leakage from the inner pipe. ${ }^{22}$ The pipes under discussion were stainless steel, the carrier pipe was $6.35 \mathrm{~mm}$ diameter, and the outer pipe was $12.7 \mathrm{~mm}$ diameter. The room temperature carrier gas flowed at $\approx 25 \mathrm{~L} / \mathrm{min}$ in the carrier pipe, or about $13 \mathrm{~m} / \mathrm{s}$ flow velocity, at $0.16 \mathrm{MPa}$ (20 psig). In the semiconductor industry, the annulus is 
sealed and pressurized with nitrogen to $0.79 \mathrm{MPa}(100$ psig). Continuous pressure monitoring alerted operators to a loss of nitrogen pressure, either a nitrogen leak into the carrier pipe or out to the room. Kumagai stated that in practice, leakage failures of the carrier gas to the room were practically nonexistent in properly assembled installations. Kumagai also said that the annulus could be evacuated rather than pressurized, but the nitrogen pressurized annulus was regarded to be simpler than a vacuum annulus and was adequate to detect leaks in either tube while not compromising safety of operating personnel. ${ }^{22}$ These semiconductor gas manifolds operated at room temperature; the process gas and the nitrogen annulus gas were also at room temperature. The operating environment was low corrosion and the gas flow rates did not cause vibration. This system had no thermal expansion, corrosion, or flow-induced vibration concerns, making this one of the few instances that the double-walled piping could reasonably be modeled as two independent pipes.

Another interesting case is the Experimental Breeder Reactor-II reactor vessel. Since the reactor was cooled by sodium, a prudent design measure of a double walled reactor vessel (a primary vessel and a guard vessel) was used. The primary vessel was basically lowered into a 'well' formed by the guard vessel. The annulus was $12.5 \mathrm{~cm}$ between the two vessels. The primary vessel was given a failure rate of $1 \mathrm{E}-08 /$ year for catastrophic failure (rupture). The vessel operated at about $370^{\circ} \mathrm{C}$. The argon cover gas in the annulus did not flow quickly enough to remove heat, so the guard vessel reached close to the same temperature. In the event of a primary vessel rupture to the annulus (e.g., due to inclusions or other metallurgical flaws), the analysts assumed that a guard vessel rupture would be very improbable. ${ }^{23}$ The term 'very improbable' is difficult to interpret but they likely meant below $1 \mathrm{E}-06 /$ demand. One common cause failure mechanism for both inner and outer vessel failure was uncontrolled overpressure of the argon cover gas in the annulus. The Argon Gas System having an overpressure event was calculated to be a frequency of $2.9 \mathrm{E}-08 /$ year (Ref. 23).

In other, more typical, situations where the carrier and outer pipes operate at different temperatures, the situation is not as straightforward and assuming pipe independence is too optimistic. A good approach to quantify the reliability of double containment piping where there can be temperature, vibration, or other effects, is to apply a Beta factor to account for the outer, non-independent pipe. The carrier pipe is given a multiplier of 0.01 to its leakage failure rate to account for the second, proximate-location pipe of the same material. Therefore, the external leak failure rate of the double containment pipe would be the carrier pipe leak failure rate multiplied by 0.01 . If the outer pipe is a different, less strong material, then a Beta factor of 0.1 is recommended. This Beta approach was put forward early in the ITER international project and remains a valid approach today. ${ }^{24,25}$ Certainly some can argue that this approach is also conservative, that the outer pipe could function better than the Beta factor suggests, especially in view of the opportunity for constant monitoring of the pipe annulus. For early reliability studies on conceptual designs, this Beta factor approach is recommended for its simplicity and speed to address the double-walled piping issue.

For designs advanced past the conceptual design level, there will be enough design information to support a detailed analysis. The two pipes can either be modeled as a primary and standby component, as mentioned above, or an engineering assessment can be performed. A rigorous finite element analysis can be performed to determine if any common modes (pipe walls touching and transferring forces, vibration through spacers or centering rings) are affecting both pipes. A corrosion assessment can be performed for both pipes to determine if there is a high likelihood of corrosion pitting or breaches in either pipe. The reliability analyst can use these analysis results to estimate the "leak tightness" of the double containment system.

\section{SOURCES OF PIPING FAILURE RATE DATA}

There are some failure rate data available in the literature that can support reliability assessments of double containment systems. Single walled carbon steel pipe data can be found in Eide. ${ }^{26}$ Fleming has some stainless steel pipe data as well as carbon steel pipe data. ${ }^{27}$ Plastic pipe failure rate data were scarce in the literature. A data point was calculated from Petro. ${ }^{28}$ The Petro data show that for polyethylene piping used in natural gas distribution systems, the failure rates are close to the failure rates of carbon steel piping used for the same purpose, giving an average failure rate on the order of $2 \mathrm{E}-08 / \mathrm{hr}-\mathrm{m}$ for gas leakage. Some data accumulated from polyvinyl chloride piping used in water distribution systems gave a point estimate leakage failure rate of 3.8E-09/hr-m (Ref. 29).

Basta discusses that detection cables used in the annulus of double piping may give false alarms; the conductivity type cables were more susceptible to false signals than the resistance cables. ${ }^{30}$ False signals were often attributed to condensed moisture from air trapped when the piping for these industrial systems was installed; the conductivity cable responded to the accumulated condensation water rather than to a process liquid. Thus, the detection cable did properly detect liquid; the signal was only 'false' in that there was no leak of process 
liquid. Condensed water within the outer pipe can create other issues due to the deleterious effects of standing water on some pipe materials (e.g., rust). Suggestions to avoid this issue were to sweep the annulus with dry nitrogen gas, or draw a vacuum on the annulus so that the initially trapped moist air is removed from the system.

\section{CONCLUSIONS}

There are some fusion facility needs for confinement that are well addressed by double containment piping. Several design guides exist to support the designer in the double pipe design, which must be performed carefully to gain all the advantages of double containment without the liabilities of premature failure. This paper presents the Beta factor method for the reliability analyst to use to quantify the leakage failure rate of a double piping system in conceptual design. A Beta factor of 0.01 can be applied to two pipes of the same material, and a Beta factor of 0.1 is recommended if the outer pipe is not as robust as the carrier pipe. For more detailed work on advanced designs, more rigorous pipe modeling can be used.

\section{ACKNOWLEDGMENTS}

This work was prepared for the US Department of Energy, Office of Fusion Energy Sciences, under the DOE Idaho Operations Office contract number DE-AC07-05ID14517.

\section{REFERENCES}

1. US Code of Federal Regulations, Title 40, Part 280, Subpart 42, "Requirements for hazardous substance underground storage tank systems," Washington, DC, February 6, 2002.

2. US Code of Federal Regulations, Title 40, Part 265, Subpart 193, "Containment and detection of releases," Washington, DC, July 7, 2010.

3. R. A. BOLMEN, Jr., Semiconductor Safety Handbook, Noyes Publications, Westwood, NJ (1998), ch. 10.

4. C. G. ZIU, Handbook of Double Containment Piping Systems, McGraw-Hill Book Company, NY (1995).

5. Engineering and Design - Liquid Process Piping, EM 1110-1-4008, Engineer Manual, US Army Corps of Engineers, Washington, DC, 2002, ch. 8.

6. Design of Secondary Containment in Petrochemical Facilities, American Society of Civil Engineers, New York, 1997, ch. 7.

7. Standard for Dual Wall Underground Steel Storage Tanks, STI 700-50-2010, Steel Tank Institute, Lake Zurich, Illinois, USA (2006).
8. P. R. BALLANTYNE, A. C. BELL, J. L. HEMMERICH, "Design features of secondary containments for the JET Active Gas Handling System and their role in mitigating both chronic and accident tritium releases," Fusion Technology, 21, 483 (1992).

9. J. L. FOSZCZ, "Building successful containment piping," Plant Engineering, 59, 58 (March 2005).

10. 2010 ASME Boiler \& Pressure Vessel Code, Section $\mathrm{XI}$, "Rules for Inservice Inspection of Nuclear Power Plant Components," subsection IWB-1220, components exempt from examination, 2011a addenda, American Society of Mechanical Engineers, New York, July 1, 2011.

11. D. CABE, "Radiography of Main Steam Piping Welds Enclosed within Guard Pipe," Materials Evaluation, 47, 1126 (1989).

12. J. M. LIU, C. P. NEMARICH, "Remote NDE Technology for Inaccessible Shipboard Piping Inspection," Journal of Failure Analysis and Prevention, 8, 193 (2008).

13. C. G. ZIU, "Plastic Double-Containment Piping Systems," Materials Performance, 31, 88 (March 1992).

14. M. FUTAKAWA and K. KIKUCHI, "Vibrational Characteristics of a Coaxial Double-Pipe," Nuclear Engineering and Design, 94, 115 (1986).

15. D. L. SMITH et al., Blanket Comparison and Selection Study - Final Report, ANL/FPP-84-1, volume 3, Argonne National Laboratory, September 1984, section 9.3.1.

16. A. E. BERGER et al., "Double-Walled Heat Exchanger Risk Analysis for Group B1 and Group B2 Refrigerants," ASHRAE Transactions, 110, 235 (2004).

17. J. KUDOU et al., "A PSA of the HTTR-IS Hydrogen Production Plant," Proceedings of the 2nd International Meeting of the Safety and Technology of Nuclear Hydrogen Production, Control, and Management, San Diego, CA, June 14-18, 2010, American Nuclear Society (2010).

18. F. NADIM et al., "Non-Uniform Regulations of Underground Storage Tanks in the United States," Spill Science \& Technology Bulletin, 6, 341 (2000).

19. G. L. EDGEMON et al., "History and Operation of the Hanford High-Level Waste Storage Tanks," Corrosion, 65, 163 (2009).

20. C. P. MARSH et al., Lipari Landfill Piping Network Corrosion Condition Assessment and Service Life Prediction Analysis, ERDC/CERL TR-08-21, US Army Corps of Engineers, December 2008. 
21. R. M. HARRINGTON and C. T. RAMSEY, Preliminary Probabilistic Design Basis Accident Evaluation of the Cold Source Facilities of the Advanced Neutron Source, ORNL/M-4606, Oak Ridge National Laboratory, 1995, p. 5-12.

22. H. Y. KUMAGAI, "Hazardous gas handling in semiconductor processing," Journal of Vacuum Science and Technology A, 8, 2865 (1990).

23. Experimental Breeder Reactor II (EBR-II) Level 1 Probabilistic Risk Assessment, revision 2, ANL EBRII PRA, Argonne National Laboratory, 1991, p. 5-27 to $5-59$.

24. L. C. CADWALLADER, Vacuum Bellows, Vacuum Piping, Cryogenic Break, and Copper Joint Failure Rate Estimates for ITER Design Use, INL/EXT-1018973, Idaho National Laboratory, 2010.

25. T. PINNA et al., "Failure Mode and Effect Analysis on ITER Heat Transfer Systems," Fusion Engineering \& Design, 42, 431 (1998).
26. S. A. EIDE et al., Industry-Average Performance for Components and Initiating Events at U.S. Commercial Nuclear Power Plants, NUREG/CR6928, US Nuclear Regulatory Commission, Washington, DC, 2007.

27. K. N. FLEMING and B. LYDELL, Pipe Rupture Frequencies for Internal Flooding PRAs, revision 1, EPRI-TR-1013141, Electric Power Research Institute, Palo Alto, CA, 2006.

28. P. P. PETRO, "Study of Plastic vs. Steel Pipe Performance," Gas Digest, 1, 14 (December 1975).

29. S. FOLKMAN, Water Main Breaks in the USA and Canada: A Comprehensive Study, Utah State University, April 2012. Report available at http://www.neng.usu.edu/.

30. N. BASTA, "Double up to contain leaks," Chemical Processing, 67, 26 (December 2004). 